\title{
Supplementation with key nutrients reduced postoperative infections and length of hospital stay after gastrointestinal surgery
}

Gianotti L, Braga M, Nespoli L, et al. A randomized controlled trial of preoperative oral supplementation with a specialized diet in patients with gastrointestinal cancer. Gastroenterology 2002;122:1763-70.

Source of funding: diets provided by

Novartis Consumer Health (Bern,

Switzerland).

For correspondence: Dr L Gianotti,

Chirurgia $3^{\circ}$, San Gerardo Hospital,

Monza, Milan, Italy.

luca.gianotti@unimib.it (POEN) with key nutrients more effective than conventional treatment (COTR) for reducing postoperative infections and length of hospital stay?

Design

Randomised (allocation concealed), unblinded, controlled trial with 30 days of follow up after hospital discharge.

\section{Setting}

Department of surgery, San Raffaele University, Milan, Italy.

\section{Patients}

305 patients (mean age 64 y, 54\% men) who had histologically documented cancer of the GI tract and planned major elective surgery. Exclusion criteria included weight loss $\geq 10 \%$ (with respect to usual body weight) in the past 6 months, age $<18$ years, and hepatic dysfunction (Child-Pugh class $>$ B). Follow up was $100 \%$.

\section{Intervention}

Patients were allocated to PSUP (n=102), POEN $(n=101)$, or COTR $(n=102)$. Before surgery, patients in the PSUP group were asked to drink one $1 / \mathrm{d}$ of Oral Impact ${ }^{\circledR}$ (Novartis Consumer Health, Bern, Switzerland), a supplemented liquid diet containing arginine $(12.5 \mathrm{~g} / \mathrm{l}), \omega-3$ fatty acid $(3.3 \mathrm{~g} / \mathrm{l})$, and RNA (1.2 g/l) for 5 consecutive days. Patients in the POEN group received the same preoperative treatment as the PSUP group plus postoperative jejunal infusion with Impact ${ }^{\circledR}$. Patients in the COTR group did not receive any artificial nutrition before or after surgery.

\section{Main outcome measures}

Incidence of postoperative infections and length of postoperative hospital stay.

\section{Main results}

Analysis was by intention to treat. Fewer patients in each of the PSUP and POEN groups than in the COTR group developed postoperative infections (table). The length of postoperative hospital stay was shorter in each of the PSUP and POEN groups than in the COTR group (table). The PSUP and POEN groups did not differ for postoperative infections or length of postoperative hospital stay (table).

\section{Conclusion}

Preoperative supplementation with or without postoperative enteral nutrition with key nutrients was more effective than conventional treatment for reducing postoperative infections and length of hospital stay in well nourished patients with cancer of the gastrointestinal tract.
Preoperative supplementation (PSUP) or PSUP plus postoperative enteral nutrition (POEN) $v$ conventional treatment (COTR) in surgery for gastrointestinal cancer at 30 days after hospital discharge*

\begin{tabular}{lllll}
\hline Outcomes & Comparison & Rate & RRR (95\% CI) & NNT (CI) \\
\cline { 2 - 5 } $\begin{array}{c}\text { Patients with } \\
\text { infectious } \\
\text { complications }\end{array}$ & PSUP $v$ COTR & $14 \% v 30 \%$ & $54 \%(21$ to 74$)$ & $6(4$ to 19$)$ \\
\cline { 2 - 5 } & POEN $v$ COTR & $16 \% v 30 \%$ & $48 \%(12$ to 70$)$ & $7(4$ to 34$)$ \\
\cline { 2 - 5 } & PSUP $v$ POEN & $14 \% v 16 \%$ & $13 \%(-66$ to 55$)$ & Not significant \\
\hline \multirow{2}{*}{$\begin{array}{c}\text { Length of hospital } \\
\text { stay (days) }\end{array}$} & PSUP $v$ COTR & $11.6 v 14.0$ & $2.4(0.6$ to 4.2$) \dagger$ \\
\cline { 2 - 5 } & POEN $v$ COTR & $12.2 v 14.0$ & $1.8(0.1$ to 3.5$) \dagger$ \\
\cline { 2 - 5 } & PSUP $v$ POEN & $11.6 v 12.2$ & $0.6(-0.6$ to 1.8$)$ \\
\hline
\end{tabular}

*Abbreviations defined in glossary; RRR, NNT, and $\mathrm{Cl}$ calculated from data in article.

†Significant differences favour PSUP and POEN.

\section{COMMENTARY}

Although the GI tract is an essential barrier to the absorption of gut antigens, it is less effective in malnourished patients. ${ }^{1}$ Hence, artificial nutritional has generally been aimed at malnourished patients or those who cannot resume normal diets soon after surgery. Recently, efforts towards strengthening patients' defences to infection have resulted in the increased use of immunonutrition. The common ingredients of immunonutrition formulas include arginine, glutamine, and omega 3 essential fatty acids. ${ }^{2-3}$

The trial by Gianotti et al differs from previous studies in that it investigated immunonutrition in nourished or well nourished patients and included an unsupplemented control group. The finding that immunonutrition was more effective than no supplementation for reducing postoperative infection in well nourished patients with cancer of the GI tract is sufficient impetus for change in standard practice.

Cost will be a factor for many clinicians in making this change in practice. Immunonutrition is expensive, and the potential savings from a decrease in expensive infectious complications and reduced length of hospital stay are not always recognised when hospital budgets are prepared. However, in considering the cost implications of this study it should be noted that the study also measured the additional benefit of POEN and found no added benefit above PSUP alone. PSUP orally by patients is not only less invasive with fewer side effects than enteral feeding but has the added advantage of allowing patients more independence. It is also likely to be a more attractive option for hospitals than POEN feeding, which requires costly equipment and is more time consuming for nursing staff to manage.

Jane Brosnahan, RCpN, BN Clinical Nurse Consultant Centre for Evidence Based Nursing Aotearoa Auckland District Health Board Auckland, New Zealand

1 Reynolds JV, O'Farrelly C, Feighery C, et al. Impaired gut barrier function in malnourished patients. Br J Surg 1996;83:1288-91.

Senkal M, Mumme A, Eickhoff U, et al. Early postoperative enteral immunonutrition: clinical outcome and cost-comparison analysis in surgical patients. Crit Care Med

3 Beale RJ, Bryg DJ, Bihari DJ. Immunonutrition in the critically ill: a systematic review of clinical outcome. Crit Care Med 1999;27:2799-805. 